\title{
Coincidence of Congenital Malformation and Embryonic Tumours of Childhood
}

\author{
COLIN L. BERRY, JEAN KEELING, and CLARE HILTON \\ From The Hospital for Sick Children, Great Ormond Street; and Institute of Child Health, London
}

\begin{abstract}
Berry, Colin L., Keeling, Jean, and Hilton, Clare (1970). Archives of Disease in Childhood, 45, 229. Coincidence of congenital malformation and embryonic tumours of childhood. Examination of the records of cases of neuroblastoma, nephroblastoma, hepatoblastoma, and teratoma has not revealed a significant association between neoplasia and malformation. An increase in 'local' abnormalities in sacrococcygeal teratomata might be explained by local growth effects. The significance of the definition of malformation, the validity of comparisons between 'general incidence' figures for malformations, and those obtained in tumour-bearing patients is considered.
\end{abstract}

Many reports of an excessive incidence of congenital abnormalities in subjects with malignant disease have appeared in recent years (Miller, 1966; Sy and Edmonson, 1968; Kobayashi, Furukawa, and Takatsu, 1968). With the exception of the association of leukaemia and Down's syndrome (Bernard et al., 1955; Carter, 1958; Krivit and Good, 1957), and the occurrence of malignant lymphomata in patients with immune deficiency states (Peterson, Cooper, and Good, 1965), the concurrence of these conditions has not been shown to be greater than could be attributed to chance, as pointed out by Sy and Edmonson when discussing neuroblastoma. However, in the survey carried out by Kobayashi et al. (1968) recording major and minor anomalies including abnormal dermatoglyphs, an extremely high incidence of malformation was found. The incidence of anomalies recorded was $35 \%$ for neuroblastoma, $58 \%$ for nephroblastoma, $45 \%$ for hepatoblastoma, and $17 \%$ for gonadal teratomas.

In an attempt to determine whether major congenital anomalies were found in greater frequency in patients presenting with malignant disease, an examination of the records of cases of neuroblastoma, nephroblastoma, hepatoblastoma, and teratoma seen at The Hospital for Sick Children, Great Ormond Street, was made. These tumours were selected to include neurectodermal, mesodermal, and germ cell origins.

\section{Results}

The anomalies found are shown in the Tables I to IV. Table V indicates the anomalies found in association with 'occult' neuroblastoma (vide infra).

Both cases of talipes equinovarus included required active treatment, and surgical correction of pes cavus (No. 4, Table IV) was necessary in the case described.

Statistical treatment consisted of the use of Poisson's exponential summation to compare expected and observed frequencies of the incidence of malformation, using the figure of 26.7 malformed/ 1000 (Leck et al., 1968) to determine the expected frequency.

The children in the group of sacrococcygeal

TABLE I

Teratomata (96 Cases)

Sacrococcygeal 63 cases
Anomalies found:
(1) Imperforate anus
(2) Rectovaginal fistula, imperforate anus
(3) Ectopia vesicae, epispadias, short penis
(4) Talipes equinovarus
(5) Oesophageal atresia, tracheo-oesophageal fistula, cystic kidney
(6) Hydrocephalus, Arnold-Chiari malformation
Anomalies found: Gonadal 17 cases
(1) Pierre-Robin syndrome
(2) Pyloric atresia
Records of $\left\{\begin{array}{l}5 \text { Mediastinal } \\ 5 \text { Intracranial } \\ 6 \text { Other }\end{array}\right\}$ Teratoma abnormalities found


TABLE II

Nephroblastoma (103 Cases)

Anomalies found:

(1) Syndactyly, talipes, left convergent squint, left facial palsy (LMN), asymmetry of features, flat right parietal region

(2) Dwarfism, vitiligo, and hyperpigmentation

(3) Aortic stenosis

(4) Hypospadias, horseshoe kidney

Other defects discovered at operation or necropsy:

(1) Solitary kidney

(2) Right duplex kidney

(3) Hypoplasia of left cerebellar hemisphere

Two cases of somatic asymmetry were also recorded

TABLE III

Hepatoblastoma (40 cases)

Anomalies found:

(1) Right diaphragmatic defect

(2) Talipes (bilateral)

Defects discovered at operation or necropsy:

(1) Meckel's diverticulum

(2) Persistent ductus arteriosus

TABLE IV

Neuroblastoma (144 Cases)

Anomalies found:

(1) Ventricular septal defect

(2) Anomalous position of aortic arch, abnormal branching

(3) Congenital dislocation of the hip

(4) Bilateral pes cavus

(5) Pyloric stenosis

Defects discovered at operation:

(1) Duplex left kidney; duplex left ureter

TABLE V

\section{Occult Neuroblastoma}

(1) Patent ductus arteriosus, diaphragmatic hernia, hypoplasia of right lung

(2) Aortic stenosis, hypoplastic aorta, patent ductus arteriosus

(3) Rubella syndrome, patent ductus arteriosus, cardiomegaly, situs inversus, abnormal spleen

(4) Atrial septal defect, ventricular septal defect, transposition of the great arteries, tricuspid atresia

(5) Portal vein malformation (diffuse), cerebellar medulloblastoma

teratomata show an increase in frequency of major malformation $(6 / 63)$ which is significant $(p=$ $0.011)$. However, if those anomalies attributable to local growth effects (see below) are excluded, the incidence $(3 / 63)$ is not significantly different from normal $(p=0 \cdot 35)$. In no other group was a significant increase in the incidence of malformation found. The probability of the observed frequency differing significantly from that expected was? $p=0.37$ for the remaining teratomata, $p=0.32 \underset{\overrightarrow{2}}{\vec{s}}$ for nephroblastoma, $p=0.30$ for hepatoblastoma, and $\mathrm{p}=0.35$ for neuroblastoma.

Defects discovered at operation or necropsy are not included in the calculations, for reasons discussed below.

\section{Discussion}

When attempting to examine the possible association of two groups of diseases, the method of comparison of figures of incidence is critical. If 'general incidence' figures of congenital malformations in a population are the basis of comparison, then the inclusion of defects discovered as a resultiv of the malignancy is not valid, since these defects $\overrightarrow{0}$ might not normally be found.

The inclusion of 'occult' tumours, such as those ${ }^{\circ}$ reported by Beckwith and Perrin (1963) and in series such as those of Sy and Edmonson, is alsomisleading. In previously reported cases, as in the 5 cases in Table V, death occurred as a result of the concurrent malformations, thereby increasing $\vec{\omega}$ the apparent incidence of abnormality associated $\sigma$ with neuroblastoma.

For our comparison, the figures of Leck et al. (1968) for the incidence of malformations in patients followed to the age of 6 years are taken as? likely to represent complete ascertainment of externally diagnosable malformations. These authors pointed out that internal malformation such $\overrightarrow{\overrightarrow{0}}$ as horseshoe kidney or Meckel's diverticulum 3 would not be recorded in this kind of survey unless they caused symptoms or were discovered at necropsy. They also found that, for similar reasons, minor but conspicuous abnormalities, e.g. accessory auricles and digits, might be missed. For this 3 reason, only major anomalies are considered in this study.

The figure of ' 26.7 malformed per 1000 ' was derived from the study of Leck et al. (1968). Othercomparable series from different centres have shown rates of between 22 and 27 per 1000 for major malformations (McDonald, 1958, 1961 N Ward and Irvine, 1961; Smithells, 1968).

It is only in the group of teratomata that there appears to be an excessive incidence of abnormalities $\omega$ if our findings are examined in a manner comparable to that used in these studies. It is of interest to note that three of the five major malformations seenes in the sacrococcygeal group of teratomata were defects of development of the hind gut and 'cloacal'응 region, and might possibly be related to the presenced of a locally proliferating tumour during develop- $\frac{?}{D}$ 


\section{Coincidence of Congenital Malformation and Embryonic Tumours of Childhood}

ment; in all of these cases the tumour mass was present at birth.

The finding of hemihypertrophy in 2 cases of nephroblastoma is in accordance with the findings of other workers (Miller, Fraumeni, and Manning, (1964). These cases, if included as congenital malformations, would increase the incidence of major anomalies associated with nephroblastoma to $6: 103$, and would suggest an association as noted by Miller (1966). However, it is not certain that hemihypertrophy is a 'congenital' defect in terms of the definition proposed by McKeown and Record (1960) -

'. . . macroscopic abnormalities of structure attributable to faulty development and present at birth,'-

and its incidence in a normal population is unknown. The absence of a significant number of abnormalities in neuroblastoma, as found by Miller (1966), is confirmed in this study.

Apart from the suggested local effects, no specific group of anomalies is found in association with any tumour, the distribution of major defects in the whole series being consistent with the 'normal' incidence of various anomalies.

From our results, any significant association between the presence of congenital abnormalities and tumours may be explained by local growth effects.

We would like to thank Dr. C. O. Carter for his helpful criticism of this paper.

C. L. Berry is the Gillson Scholar of the Worshipful Society of Apothecaries of London. Clare Hilton is British Empire Cancer Campaign Research Fellow.

\section{REFERENCES}

Beckwith, J. B., and Perrin, E. V. (1963). In situ neuroblastomas: a contribution to the natural history of neural crest tumors. American Fournal of Pathology, 43, 1089.

Bernard, J., Mathe, G., Delorme, J. C., and Barnoud, O. (1955). Les leucoses des très jeunes enfants. Archives Françaises de Pédiatrie, 12, 470.

Carter, C. O. (1958). A life-table for mongols with the causes of death. Fournal of Mental Deficiency Research, 2, 64.
Kobayashi, N., Furukawa, T., and Takatsu, T. (1968). Congenital anomalies in children with malignancy. Paediatria Universitatis Tokyo, 16, 31 .

Krivit, W., and Good, R. A. (1957). Simultaneous occurrence of mongolism and leukemia: a report of a nationwide survey. American fournal of Diseases of Children, 94, 289.

Leck, I., Record, R. G., McKeown, T., and Edwards, J. H. (1968). The incidence of malformations in Birmingham, England, 1950-1959. Teratology, 1, 263.

McDonald, A. D. (1958). Maternal health and congenital defect. A prospective investigation. New England Fournal of Medicine, 258, 767.

- (1961). Maternal health in early pregnancy and congenital defect. Final report on a prospective inquiry. British fournal of Preventive and Social Medicine, 15, 154.

McKeown, T., and Record, R. G. (1960). Malformations in a population observed for five years after birth. In Ciba Foundation Symposium on Congenital Malformations, p. 2 . Ed. by G. E. W. Wolstenholme and C. M. O'Connor. Churchill, London.

Miller, R. W. (1966). Relation between cancer and congenital defects in man. Nerw England fournal of Medicine, 275, 87.

- Fraumeni, J. F., Jr., and Manning, M. D. (1964). Association of Wilms's tumor with aniridia, hemihypertrophy and other congenital malformations. New England fournal of Medicine, 270, 922.

Peterson, R. D. A., Cooper, M. D., and Good, R. A. (1965). Disorders of the thymus and other lymphoid tissues. Progress in Medical Genetics, $4,1$.

Smithells, R. W. (1968). Incidence of congenital abnormalities in Liverpool, 1960-64. British Fournal of Preventive and Social Medicine, 22, 36.

Sy, W. M. and Edmonson, J. H. (1968). The developmental defects associated with neuroblastoma: etiologic implications. Cancer (Philadelphia), 22, 234.

Ward, I. V., and Irvine, E. D. (1961). Incidence of congenital abnormality in infants born to Exeter mothers, 1954-60 inclusive. Medical Officer, 106, 381.

\section{Addendum}

Since this paper was prepared for publication we have noticed two further articles which have failed to show an association between congenital malformations and tumours (Li and Fraumeni, 1969; Shanklin and SoteloAvila, 1969).

\section{REFERENCES}

Li, F. P., and Fraumeni, J. F., Jr. (1969). Rhabdomyosarcoma in children: epidemiologic study and identification of a familial cancer syndrome. Fournal of the National Cancer Institute, 43, 1365.

Shanklin, D. R., and Sotelo-Avila, C. (1969). In situ tumors in fetuses, newborns and young infants. Biologia Neonatortu, 14, 286.

Correspondence to Dr. C. L. Berry, Institute of Child Health, 30 Guilford Street, London W.C.1. 